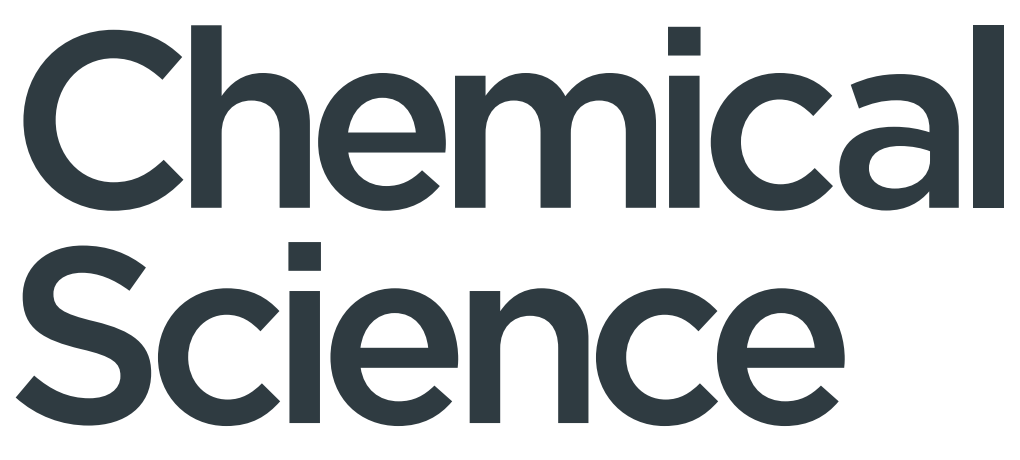

Volume 11

Number 2

14 January 2020

Pages 297-604

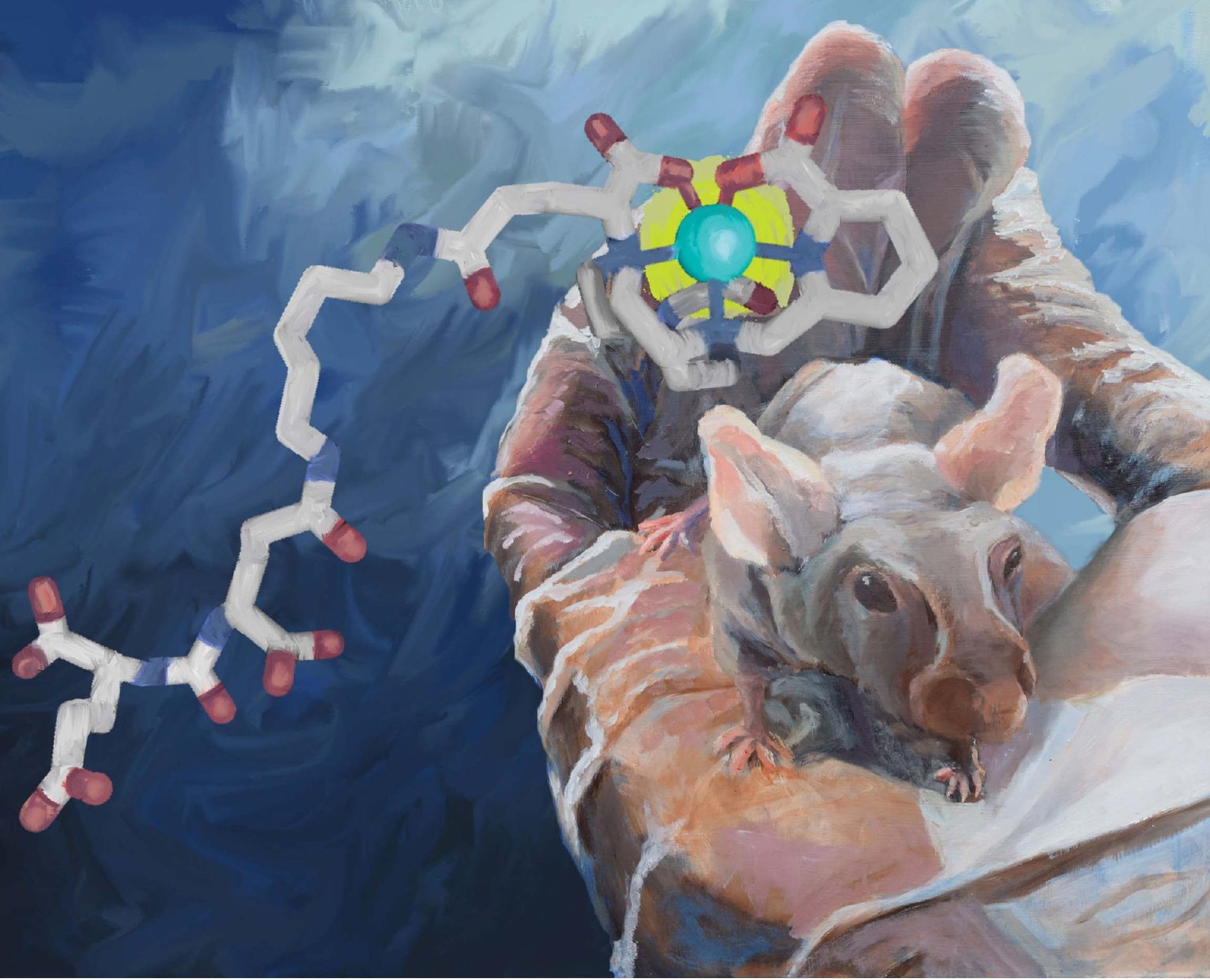

ISSN 2041-6539 
Check for updates

Cite this: Chem. Sci., 2020, 11, 333

๑ All publication charges for this article have been paid for by the Royal Society of Chemistry

Received 14th September 2019 Accepted 17th November 2019

DOI: $10.1039 / c 9 s c 04655 k$

rsc.li/chemical-science

\section{Chelation with a twist: a bifunctional chelator to enable room temperature radiolabeling and targeted PET imaging with scandium-44 $\uparrow$}

\author{
Brett A. Vaughn, ${ }^{a}$ Shin Hye Ahn, ${ }^{a}$ Eduardo Aluicio-Sarduy, ${ }^{b}$ Justin Devaraj, \\ Aeli P. Olson, ${ }^{b}$ Jonathan Engle ${ }^{b}$ and Eszter Boros (D)*a
}

Scandium-44 has emerged as an attractive, novel PET radioisotope with ideal emission properties and halflife $\left(t_{1 / 2}=3.97 \mathrm{~h}, E_{\text {mean }} \beta^{+}=632 \mathrm{keV}\right)$ well matched to the pharmacokinetics of small molecules, peptides and small biologics. Conjugates of the current gold-standard chelator for ${ }^{44} \mathrm{Sc}, 1,4,7,10$-tetraazacyclododecane-1,4,7,10-tetraacetic acid (DOTA), require heating to achieve radiochemical complexation, limiting application of this isotope in conjunction with temperature-sensitive biologics. To establish Sc(III) isotopes as broadly applicable tools for nuclear medicine, development of alternative bifunctional chelators is required. To address this need, we characterized the Sc(III)-chelation properties of the smallcavity triaza-macrocycle-based, picolinate-functionalized chelator $\mathrm{H}_{3}$ mpatcn. Spectroscopic and radiochemical studies establish the [Sc(mpatcn)] complex as kinetically inert and appropriate for biological applications. A proof-of-concept bifunctional conjugate targeting the prostate-specific membrane antigen (PSMA), picaga-DUPA, chelates ${ }^{44} \mathrm{Sc}$ to form ${ }^{44} \mathrm{Sc}$ (picaga)-DUPA at room temperature

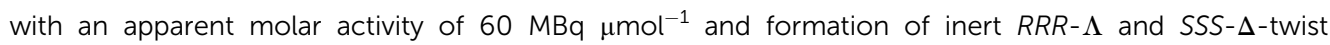
isomers. Sc(picaga)-DUPA exhibits a $K_{\mathrm{i}}$ of $1.6 \mathrm{nM}$ for PSMA, comparable to the ${ }^{18} \mathrm{~F}$-based imaging probe DCFPyL $\left(K_{\mathrm{i}}=1.1 \mathrm{nM}\right)$ currently in phase 3 clinical trials for imaging prostate cancer. Finally, we successfully employed ${ }^{44} \mathrm{Sc}$ (picaga)-DUPA to image PSMA-expressing tumors in a preclinical mouse model, establishing the picaga bifunctional chelator as an optimal choice for the ${ }^{44}$ SC PET nuclide.

\section{Introduction}

The concept of personalized medicine, where patient treatment is performed according to an individually tailored treatment regime, is an emerging clinical management paradigm. In nuclear medicine, this approach is realized by exploiting diagnostic techniques, such as non-invasive imaging by means of Positron Emission Tomography (PET) and Single Photon Emission Computed Tomography (SPECT), followed by individualized radiotherapeutic treatment. If the same molecular targeting vector is labeled with a diagnostic and a therapeutic radionuclide and utilized for sequential imaging and treatment, the approach is considered theragnostic. ${ }^{1-3}$ Ideally, the employed radionuclides represent a matched pair, where both are radioisotopes of the same chemical element; ${ }^{4}$ however, only few elements have isotopes with suitable emission properties for this purpose, thus clinical applications have focused on perceived chemical

${ }^{a}$ Department of Chemistry, Stony Brook University, 100 Nicolls Road, Stony Brook, 11790, New York, USA. E-mail: eszter.boros@stonybrook.edu

${ }^{b}$ Medical Physics Department, University of Wisconsin-Madison, 1111 Highland Avenue, Madison, 53705, Wisconsin, USA

$\dagger$ Electronic supplementary information (ESI) available. See DOI: 10.1039/c9sc04655k homologues ${ }^{68} \mathrm{Ga}$ (III) for PET imaging and ${ }^{177} \mathrm{Lu}$ (III) for subsequent radiotherapy. ${ }^{5}$ The vast differences in coordination chemistry of these two metal ions create different chemical and biological behaviors between the corresponding radiolabeled agents: $\mathrm{Ga}(\mathrm{III})$ and $\mathrm{Lu}(\mathrm{III})$ coordinate to $1,4,7,10$ tetraazacyclododecane-1,4,7,10-tetra-acetic acid (DOTA)complexes, but while Lu(III) is coordinated by all carboxylic acid groups of the octadentate DOTA, Ga(III) forms a six-coordinate complex, leaving two carboxylates in the Ga-DOTA-complex uncoordinated. ${ }^{6,7}$ This results in well-documented differences between the ${ }^{68} \mathrm{Ga}$ and ${ }^{177} \mathrm{Lu}$-complexes' lipophilicity, receptor binding affinity and in vivo biodistribution. ${ }^{6,8-10}$ Consequently, ${ }^{68} \mathrm{Ga}$-complexes' biodistribution is an imperfect predictor of ${ }^{177} \mathrm{Lu}$ compounds' dosimetry. ${ }^{\mathbf{1 1 , 1 2}}$ Better theragnostic radionuclide pairs are needed (Table 1 ), and ${ }^{44} \mathrm{Sc} /{ }^{47} \mathrm{Sc}$ are ideally suited for this purpose.

${ }^{44} \mathrm{Sc}\left(E_{\left\langle\beta^{+}\right\rangle}=632 \mathrm{keV}, t_{1 / 2}=3.97 \mathrm{~h}\right)$ has ideal properties for PET imaging. The Sc(III) ion is a closer chemical match to Lu(III) than $\mathrm{Ga}(\mathrm{III})$; therefore ${ }^{44} \mathrm{Sc}$ represents a better diagnostic partner to therapeutic ${ }^{177} \mathrm{Lu},{ }^{13}$ as for instance, both trivalent ions prefer octacoordination of DOTA-type ligands. Additionally, the emission properties of ${ }^{47} \mathrm{Sc}\left(E_{\left\langle\beta^{-}\right\rangle}=162 \mathrm{keV}, t_{1 / 2}=80.38 \mathrm{~h}\right.$, Table $1)^{14}$ are comparable to ${ }^{177} \mathrm{Lu}\left(E_{\left\langle\beta^{-}\right\rangle}=134 \mathrm{keV}, t_{1 / 2}=159.5 \mathrm{~h}\right) .{ }^{15}$ Like ${ }^{177} \mathrm{Lu},{ }^{47} \mathrm{Sc}$ emits characteristic $\gamma$-rays with an ideal energy 
Table 1 Properties of scandium isotopes in comparison with the currently used theragnostic pair ${ }^{68} \mathrm{Ga} /{ }^{177} \mathrm{Lu}$

\begin{tabular}{|c|c|c|}
\hline tope (half-life) & $E_{\left\langle\beta^{+/-}\right\rangle}$ & Production route \\
\hline $\mathrm{sa}(67.71 \mathrm{~min})$ & $830 \mathrm{keV}\left(\beta^{+}\right)$ & $\begin{array}{l}\text { Generator: }{ }^{68} \mathrm{Ge} /{ }^{68} \mathrm{Ga} \\
\text { Cyclotron }(15-6 \mathrm{MeV}){ }^{68} \mathrm{Zn}(\mathrm{p}, \mathrm{n}){ }^{68} \mathrm{Ga}\end{array}$ \\
\hline Sc $(3.97 \mathrm{~h})$ & $632 \mathrm{keV}\left(\beta^{+}\right)$ & $\begin{array}{l}\text { Generator: }{ }^{44} \mathrm{Ti} /{ }^{44} \mathrm{Sc} \\
\text { Cyclotron }(14-6 \mathrm{MeV}):{ }^{44} \mathrm{Ca}(\mathrm{p}, \mathrm{n}){ }^{44} \mathrm{Sc}\end{array}$ \\
\hline${ }^{47} \mathrm{Sc}(80.38 \mathrm{~h})$ & $162 \mathrm{keV}\left(\beta^{-}\right)$ & $\begin{array}{l}\text { Cyclotron }(30-10 \mathrm{MeV}):{ }^{50} \mathrm{Ti}(\mathrm{p}, \alpha)^{47} \mathrm{Sc} \\
\text { Reactor: }{ }^{46} \mathrm{Ca}(\mathrm{n}, \gamma)^{47} \mathrm{Ca} \rightarrow{ }^{47} \mathrm{Sc}\end{array}$ \\
\hline${ }^{7} \mathrm{Lu}(6.647 \mathrm{~d})$ & $134 \mathrm{keV}\left(\beta^{-}\right)$ & $\begin{array}{l}\left.\text { Reactor: }{ }^{176} \mathrm{Lu}(\mathrm{n}, \gamma)\right)^{177} \mathrm{Lu} \\
\text { Reactor: }{ }^{176} \mathrm{Yb}(\mathrm{n}, \gamma){ }^{177} \mathrm{Yb} \rightarrow{ }^{177} \mathrm{Lu}\end{array}$ \\
\hline
\end{tabular}

$\left(E_{\gamma}=159 \mathrm{keV}\right)$ for SPECT imaging. ${ }^{4}$ The increased availability of ${ }^{44} \mathrm{Sc}$ has prompted preclinical in vitro and in vivo studies with DOTA-conjugated biomolecules. ${ }^{13,16}$ DOTA is currently considered the gold standard scandium(III) chelator, but the slow complexation kinetics require radiolabeling at $70-95{ }^{\circ} \mathrm{C}$ for at least 30 minutes, ${ }^{17}$ which is incompatible with the labeling of antibodies. ${ }^{18}$ Functionalized DOTA is not ideal for the complexation of scandium isotopes with respect to applications with temperature-sensitive biologics and room temperaturecompatible kit formulations..$^{17,19,20}$ Furthermore, a strong preference for the formation of kinetically labile "out-of-cage" complexes with various DOTA-type derivatives has been observed. ${ }^{20,21}$ Hexadentate and acyclic chelators coordinate $\mathrm{Sc}(\mathrm{III})$ more rapidly than DOTA, ${ }^{22}$ but with a markedly reduced inertness of corresponding complexes and rapid release of $\operatorname{Sc}\left(\right.$ III). ${ }^{19}$

The coordination chemistry of the Sc(III) ion resembles that of $\mathrm{Y}(\mathrm{III})$ and $\mathrm{Lu}(\mathrm{III})$ but is dominated by its smaller ionic radius and preference for chemically hard donor ions (carboxylates, aliphatic amines). ${ }^{19,23}$ The formation of stable hydroxide coordinating complex species has been documented. ${ }^{19}$ The significantly smaller ionic radius of Sc(III) indicates a preference for chelators with smaller ion binding cavities, disfavoring the formation of labile out-of-cage complexes. Small-cavity chelators may be better suited to coordinate ${ }^{44} \mathrm{Sc}$ (III) under mild, low temperature conditions without formation of the problematic "out-of-cage" intermediate species.

Recently, the feasibility of this approach has been demonstrated using the heptadentate chelator 1,4-bis(carboxymethyl)6-[bis(carboxymethyl)]amino-6-methyl-perhydro-1,4-diazepine

(AAZTA, Fig. 1), which forms kinetically inert and thermodynamically stable $\mathrm{Sc}(\mathrm{III})$-complexes at room temperature and provides a viable alternative to DOTA. ${ }^{24,25}$ However, the hydrophilicity of the corresponding complexes can result in accelerated excretion and diminished accumulation in the site of interest. We sought to develop alternative, more lipophilic chelator structures that would enable robust room temperature radiolabeling with $\mathrm{Sc}$ (III) isotopes and form kinetically inert complexes, especially in their bifunctional form.

Inspired by lanthanide chemistry, we designed bifunctional chelators for scandium isotopes using the following criteria: (1) radiolabeling must be rapid at room temperature and $\mathrm{pH} 4$, to enable kit formulations and the labeling of temperaturesensitive biomolecules (2) the chelator must disfavor the
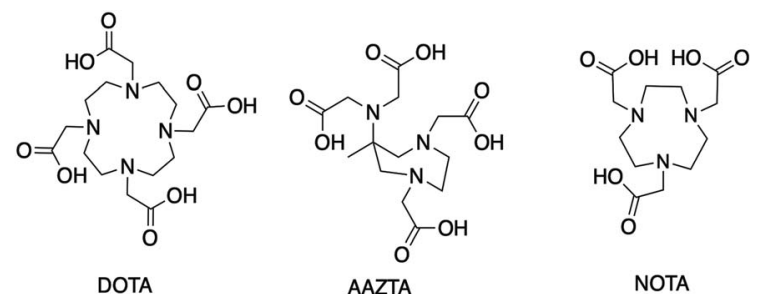

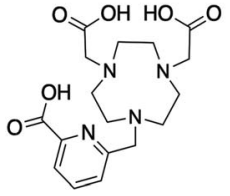

$\mathrm{H}_{3}$ mpatcn

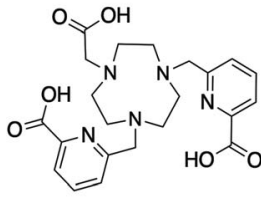

$\mathrm{H}_{3}$ bpatcn

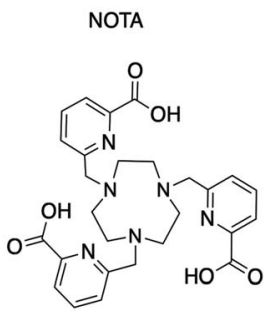

$\mathrm{H}_{3}$ tpaten
Fig. 1 (Top) Ligand structures DOTA, AAZTA and NOTA, previously explored with Sc(III) isotopes. (Bottom) Chelator library explored in this work.

formation of an out-of-cage complex to prevent the formation of labile, intermediate complex species (3) the formed complex must be kinetically inert to transchelation in vitro and in vivo, (4) functionalization of the ligand must be feasible without negatively impacting radiolabeling properties or the kinetic inertness of the formed complex ${ }^{24}$ and (5) integration of a lipophilic moiety to enhance binding affinity to biological targets and slow renal clearance.

Here, we show that a small-cavity, triaza-macrocycle based chelator exhibits excellent properties for the chelation of Sc(III) and corresponding targeted nuclear medicine applications with the PET isotope ${ }^{44} \mathrm{Sc}$.

\section{Experimental section}

\section{Materials and methods}

All starting materials were purchased from Acros Organics, Alfa Aesar, Sigma Aldrich, or TCI America and used without further purification. NMR spectra $\left({ }^{1} \mathrm{H},{ }^{13} \mathrm{C}, \mathrm{HSQC}, \mathrm{HMBC}\right)$ were collected on a $700 \mathrm{MHz}$ Avance III Bruker, $500 \mathrm{MHz}$ or $400 \mathrm{MHz}$ Bruker instrument at $25{ }^{\circ} \mathrm{C}$ and processed using TopSpin 3.5pl7. ${ }^{45} \mathrm{Sc}$ NMR was recorded on a $400 \mathrm{MHz}$ Avance III Bruker instrument at $25^{\circ} \mathrm{C}$. Chemical shifts are reported as parts per million (ppm). Mass spectrometry: low-resolution electrospray ionization (ESI) mass spectrometry and high-resolution (ESI) mass spectrometry were carried out at the Stony Brook University Institute for Chemical Biology and Drug Discovery (ICB\&DD) Mass Spectrometry Facility with an Agilent LC/MSD and Agilent LC-UV-TOF spectrometers, respectively. UV-Vis spectra were collected with the NanoDrop ${ }^{1} \mathrm{C}$ instrument (AZY1706045). Spectra were recorded from 190 to $850 \mathrm{~nm}$ in a quartz cuvette with $1 \mathrm{~cm}$ path length. HPLC: preparative HPLC was carried out using a Shimadzu HPLC-20AR equipped with a Binary Gradient, pump, UV-Vis detector, manual injector on a Phenomenex Luna C18 column $(250 \mathrm{~mm} \times 21.2 \mathrm{~mm}, 100 \AA$, AXIA packed). Method A (preparative purification method): $A=$ 
$0.1 \%$ TFA in water, $B=0.1 \%$ TFA in MeCN. Gradient: $0-5$ min: 95\% A. 5-24 min: 5-95\% B gradient. Method B (preparative purification method): $A=10^{-2} \mathrm{M}$ ammonium formate in water, $B=10 \% 10 \mathrm{mM}$ ammonium formate in water, 90\% MeCN. Gradient: 0-5 min: 95\% A. 5-24 min: 5-95\% B gradient. RadioHPLC analysis was carried out using a Shimadzu HPLC-20AR equipped with a binary gradient, pump, UV-Vis detector, autoinjector and Laura radiodetector on a Gemini-NX C18 column (100 mm $\times 3 \mathrm{~mm}, 110 \AA$, AXIA packed). Method C: $A=0.1 \%$ TFA in water, $B=0.1 \%$ TFA in MeCN with a flow rate of 0.8 $\mathrm{mL} \min ^{-1}$, UV detection at 260 and $280 \mathrm{~nm}$ or using method D, performed on a DIONEX Ultimate 300 HPLC system controlled with the Chromeleon v6.80 software. A reverse-phase $250 \times$ $4.6 \mathrm{~mm} \mathrm{C18} 5 \mu 120$ A column (DIONEX) was employed with a gradient of $A=0.1 \%$ TFA in water, $B=0.1 \%$ TFA in MeCN. The following gradient was employed: $0-3.5 \mathrm{~min}: 5 \% \mathrm{~B} ; 3.5-$ 13 min: 5-35\% B; 13-15 min: 35-90\% B; 15-19 min: 90\% B; 1519 min: $90-5 \% \mathrm{~B} ; 20-24 \mathrm{~min}: 5 \% \mathrm{~B}$; and $1 \mathrm{~mL}$ flow rate and UV detection at 220 and $254 \mathrm{~nm}$. Benzyl tert-butyl-2(methylsulfonyloxy)glutarate and tert-butyl-6-(bromomethyl)-2pyridinecarboxylate were synthesized according to previously published procedures. A detailed account of the chemical synthesis of mpatcn, picaga-DUPA and the DOTA-DUPA derivatives including NMR spectral assignments and corresponding data is provided in the ESI. $\dagger$

\section{Scandium complexation}

To obtain a single Sc-species in solution, the following general protocol was employed: ligand $(0.02 \mathrm{mmol})$ previously deprotected under acidic conditions was dissolved in $\mathrm{DI} \mathrm{H}_{2} \mathrm{O}(1 \mathrm{~mL})$. Solutions of $\mathrm{ScCl}_{3} \cdot 6 \mathrm{H}_{2} \mathrm{O}(0.02 \mathrm{mmol})$ were dissolved in $\mathrm{H}_{2} \mathrm{O}$ (1 $\mathrm{mL}$ ) and one-half molar equivalent added to each ligand solution. The $\mathrm{pH}$ of the resulting acidic solution was subsequently adjusted from $\mathrm{pH} 3$ to 6 by drop-wise addition of $1 \mathrm{M} \mathrm{NaOH}$. The mixture was subsequently heated at $80{ }^{\circ} \mathrm{C}$ for 0.5 hours to ensure complete complexation. The resulting aqueous solutions were lyophilized overnight to afford the scandium complexes as an off-white powder.

Na[Sc(DOTA)]. ${ }^{45} \mathrm{Sc}$ NMR (97.15 $\left.\mathrm{MHz}, \mathrm{D}_{2} \mathrm{O}\right): 90.9 \mathrm{ppm}$. Calculated monoisotopic mass for $\left(\mathrm{C}_{16} \mathrm{H}_{25} \mathrm{~N}_{4} \mathrm{O}_{8} \mathrm{Sc}\right)$ : 446.12; found: $m / z=447.1[\mathrm{M}+\mathrm{H}]^{+}$.

[Sc(mpatcn)]. ${ }^{1} \mathrm{H}$ NMR $\left(400 \mathrm{MHz}, \mathrm{D}_{2} \mathrm{O}\right): 8.13(\mathrm{t}, J=7.85 \mathrm{~Hz}$, 1H), 7.97 (d, $J=7.45 \mathrm{~Hz}, 1 \mathrm{H}), 7.61$ (d, $J=7.85 \mathrm{~Hz}, 1 \mathrm{H}), 4.44(\mathrm{~s}$, 2H), 3.78 (m, 2H), 3.43 (m, 2H), 2.93-3.24 (m, 12H). ${ }^{45} \mathrm{Sc} \mathrm{NMR}$ (97.15 MHz, $\left.\mathrm{D}_{2} \mathrm{O}\right): 80 \mathrm{ppm}$. Calculated monoisotopic mass for $\left(\mathrm{C}_{17} \mathrm{H}_{21} \mathrm{~N}_{4} \mathrm{O}_{6} \mathrm{Sc}\right): 422.10$; found: $m / z=423.1[\mathrm{M}+\mathrm{H}]^{+}$.

[Sc(EDTA) $\left(\mathrm{H}_{2} \mathrm{O}\right)_{2}$ ]. ${ }^{1} \mathrm{H}$ NMR $\left(400 \mathrm{MHz}, \mathrm{D}_{2} \mathrm{O}\right): 3.43(\mathrm{~m}, 4 \mathrm{H})$, $3.28(\mathrm{~m}, 4 \mathrm{H}) .{ }^{45} \mathrm{Sc} \mathrm{NMR}\left(400 \mathrm{MHz}, \mathrm{D}_{2} \mathrm{O}\right): 50.5 \mathrm{ppm}$ Calculated monoisotopic mass for $\left(\mathrm{C}_{17} \mathrm{H}_{21} \mathrm{~N}_{4} \mathrm{O}_{6} \mathrm{Sc}\right)$ : 422.10; found: $m / z=$ $423.1[\mathrm{M}+\mathrm{H}]^{+}$.

\section{Acid-mediated dissociation kinetics}

Solutions of $\mathrm{ScCl}_{3}$ were prepared by dissolving $\mathrm{ScCl}_{3} \cdot 6 \mathrm{H}_{2} \mathrm{O}$ in $0.2 \mathrm{M} \mathrm{HCl}$ at a concentration of $35 \mathrm{mM}$. The solutions of the [Sc(mpatcn)] complex for kinetic measurements were prepared by mixing the ligand (L) and $\mathrm{ScCl}_{3}$ stock solutions to give a final
$1: 1 \mathrm{~L}: \mathrm{Sc}$ molar ratio and adjustment of the $\mathrm{pH}$ to 5.5 with $0.1 \mathrm{M} \mathrm{KOH}$. Complex formation was confirmed using ${ }^{1} \mathrm{H}$ and ${ }^{45} \mathrm{Sc}$ NMR spectroscopy. Dissociation of [Sc(mpatcn)] complex was followed by using UV-Vis spectroscopy. Decomplexation was quantified by plotting the change in absorbance over time at $284 \mathrm{~nm}$. Complex concentration was $0.1 \mathrm{mM}$ and dissociation experiments were performed in aq. $\mathrm{HCl}(0.1-3.0 \mathrm{M}) .{ }^{19}$

\section{Radioactive scandium complexes}

Production of 44Sc. Sc-44 was produced on a GE PETtrace cyclotron via the ${ }^{\text {nat }} \mathrm{Ca}[\mathrm{p}, \mathrm{n}]{ }^{44} \mathrm{Sc}$ nuclear reaction using pressed targets of metallic calcium ( $\sim 350 \mathrm{mg})$. Irradiations were performed at nominal $16 \mathrm{MeV}$ proton beam energy and a current of $15 \mu \mathrm{A}$ for $1-1.5 \mathrm{~h}$ with direct water cooling to the back of the target. Radiochemical separation of the produced ${ }^{44} \mathrm{Sc}$ was performed by single column extraction chromatography using a modified version of a previously reported work $^{\mathbf{2 6}}$ with a $N, N, N^{\prime}, N^{\prime}$-tetrakis-2-ethylhexyldiglycolamide functionalized resin (DGA-branched, Eichrom). Briefly, the target was dissolved in $10 \mathrm{~mL}$ of $9 \mathrm{M} \mathrm{HCl}$ and passed through a column filled with DGA resin $(\sim 120 \mathrm{mg})$, trapping the ${ }^{44} \mathrm{Sc}^{3+}$ and eluting bulk $\mathrm{Ca}^{2+}$. Next, the column was rinsed with $20 \mathrm{~mL}$ of $4 \mathrm{M} \mathrm{HCl}$ to remove remaining $\mathrm{Ca}^{2+}$. Trace metal impurities $(\mathrm{Zn}, \mathrm{Fe}$, and $\mathrm{Cu})$ were removed by a $12 \mathrm{~mL}$ wash with $1 \mathrm{M} \mathrm{HNO}_{3}$. Finally, the ${ }^{44} \mathrm{Sc}^{3+}$ was eluted in $0.1 \mathrm{M} \mathrm{HCl}(4 \times 500 \mu \mathrm{L}$ fractions $)$. Radionuclidic and chemical purity were confirmed by high purity germanium (HPGe) gamma spectrometry and microwave plasma atomic emission spectroscopy (MP-AES), respectively.

Radiolabeling with ${ }^{44} \mathrm{Sc}$. The ability of the different chelators to complex ${ }^{44} \mathrm{Sc}^{3+}$ ions was determined by incubating aliquots of ${ }^{44} \mathrm{Sc}^{3+}(0.27-0.6 \mathrm{MBq}$ in $7.5-20 \mu \mathrm{L})$ with increasing ligand or conjugate concentrations (0-20 nmol) in $0.25 \mathrm{M}$ NaOAc buffer solution $(\mathrm{pH}=4)$ for 10,30 or $60 \mathrm{~min}$ at 25 or $80{ }^{\circ} \mathrm{C}$. The total reaction volume for each radiochemical labeling was $0.21 \mathrm{~mL}$. To compute apparent molar activity, ${ }^{44} \mathrm{Sc}^{3+}$ activity in $\mathrm{MBq}$ was divided by twice the number of moles of chelator required to complex $50 \%$ of the radioactivity, and the value was reported in

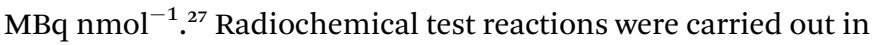
triplicate, with yields reported as averages of triplicates. Plasma stability (in duplicate) was tested by incubation of $20 \mu \mathrm{L}$ radiolabeled complex solution in $180 \mu \mathrm{L}$ rat plasma at $37{ }^{\circ} \mathrm{C}$. The time-dependent complexation yield for each ${ }^{44} \mathrm{Sc}^{3+} /$ ligand ratio and the time-dependent plasma stability were determined by autoradiography-visualized thin-layer chromatography (radioTLC) using aluminum-backed normal phase (silica) TLCplates as the stationary phase and $50 \mathrm{mM}$ EDTA as the mobile phase. Under these conditions, free radiometals move with the solvent front $\left(R_{\mathrm{f}}=1\right)$ and DOTA- or mpatcn-complexed ${ }^{44} \mathrm{Sc}$ remains at $R_{\mathrm{f}}=0.1$ or $R_{\mathrm{f}}=0$, respectively. Radioactivity distribution on TLC plates was visualized and quantified using a Packard Cyclone phosphor plate reader.

Preparation of ${ }^{44} \mathrm{Sc}$-based PSMA tracers for injection. $0.1 \mathrm{~mL}$ of sodium citrate $(150 \mathrm{mM}, \mathrm{pH} 4.5)$ was added to $10 \mathrm{nmol}$ of ligand in $0.1 \mathrm{~mL} \mathrm{DI} \mathrm{H}_{2} \mathrm{O} .{ }^{44} \mathrm{ScCl}_{3}(3.7-14.8 \mathrm{MBq}$ in $500 \mu \mathrm{L}$ dilute $\mathrm{HCl}$ ) was added, and the reaction mixture was heated at $80^{\circ} \mathrm{C}$ for $30 \mathrm{~min}$. Subsequent reaction monitoring was done by analytical 
HPLC, method D. The reaction mixture was purified using solid phase extraction (C18 Sep Pak, Waters). Unchelated ${ }^{44} \mathrm{Sc}$ is eluted with $100 \% \mathrm{H}_{2} \mathrm{O}$, followed by elution of the desired ${ }^{44} \mathrm{Sc}$-complex with a $1: 9 \mathrm{EtOH}: \mathrm{H}_{2} \mathrm{O}$ mixture. The eluate was collected and concentrated in vacuo and reconstituted in PBS for in vivo injection. $R_{\mathrm{t}}$ (method D): ${ }^{44} \mathrm{Sc}$ (picaga)-DUPA: stereoisomers elute at 10.41/10.95 $\mathrm{min} ;{ }^{44} \mathrm{Sc}$ (DOTA)-DUPA: $9.24 \mathrm{~min}$; free ${ }^{44} \mathrm{Sc}: 2.99 \mathrm{~min}$.

\section{Radioactive displacement assay}

The inhibition constant $\left(K_{\mathrm{i}}\right)$ of Sc-labeled PSMA inhibitors was determined by a radiochemical displacement assay using the known, metal-based PSMA-inhibitor MIP-1427. Sc-complexed compounds were dissolved in $\mathrm{H}_{2} \mathrm{O}$ and 10 concentrations were prepared ranging from $10^{-13}$ to $10^{-5} \mathrm{M}$. PC-3 PiP cells $(2 \times$ $10^{5}$ cells per tube in $2 \mathrm{~mL}$ Eppendorf tubes) were incubated for $40 \mathrm{~min}$ with $17.9 \mu \mathrm{Ci}(0.662 \mathrm{MBq}){ }^{99 \mathrm{~m}} \mathrm{Tc}-\mathrm{MIP}-1427$ and $0.01 \mathrm{nM}$ to $100 \mu \mathrm{M} \mathrm{Sc}$ (picaga)-DUPA, Sc(DOTA)-DUPA, or DCFPyL PSMA inhibitors in PBS pH 7.4 with $1 \%$ FBS at $37{ }^{\circ} \mathrm{C}$. Nonspecific binding was determined by adding $10 \mathrm{mM}$ DCFPyL and subtracting measured residually bound activity from total binding values obtained for subsequent samples. The cells were then washed with PBS, centrifuged, and the amount of radioactivity remaining in the cell pellet was measured on a gamma counter. Specific binding was calculated as the difference between total binding and nonspecific binding. The $K_{\mathrm{i}}$ was determined by nonlinear regression analysis using GraphPad Prism software.

\section{PET imaging and biodistribution}

All animal experiments and procedures were performed in accordance with the National Institutes of Health's "Guide for the Care and Use of Laboratory Animals" and approved by Institutional Animal Care and Use Committee (IACUC) at Stony Brook Medicine. Male NCr nude mice (6 weeks, Taconic Biosciences, Rensselaer, NY) were implanted subcutaneously on the right shoulder with $0.7-0.9 \times 10^{6}$ PC-3 PiP cells and on the left shoulder with $0.7-0.9 \times 10^{6}$ PC-3 flu cells suspended in Matrigel $(1: 1)$. When the tumors reached $50-100 \mathrm{~mm}^{3}$, the mice were anesthetized with isoflurane, and 0.6-3.0 MBq (15-82 $\mu \mathrm{Ci})$ of the tracer $(3-30 \mu \mathrm{g})$ was intravenously injected via tail vein catheter. Mice were imaged at 90 min post injection (p.i.) using Siemens Inveon PET/CT Multimodality System, and images were reconstructed using ASIPro software. Region of interest (ROI) analyses on all images were performed using AMIDE. Upon completion of imaging at 120 min p.i., mice were sacrificed, and select organs were harvested. Radioactivity was counted by using a gamma counter, and the radioactivity associated with each organ was expressed as \% ID per g. Biodistribution data were assessed by unpaired $t$-tests using GraphPad Prism to determine if differences between groups were statistically significant $(p<0.05)$.

\section{Results and discussion}

\section{Ligand design and screening with ${ }^{44} \mathrm{Sc}$}

We hypothesized that an octa- or heptadentate, triazamacrocycle based chelator would exhibit suitable complexation properties with Sc(III) without significant formation of the labile out-of-cage complex and form robust, kinetically inert radiochemical complexes compatible with in vivo applications. The introduction of picolinic acid donor arms increases the number of coordinating donors and imparts additional rigidity to formed complexes; the corresponding picolinate-functionalized triaza-macrocycle chelates show high kinetic inertness and slow interconversion of $R R R-\Lambda$ and $S S S-\Delta$ complex isomers, especially with small lanthanides. ${ }^{28-30} \mathrm{We}$ synthesized a chelator library based on picolinic acidfunctionalized triaza-cyclononane (ESI $\dagger$ ). $\mathrm{H}_{3}$ mpatcn, $\mathrm{H}_{3}$ bpatcn and $\mathrm{H}_{3}$ tpatcn (Fig. 1) were tested for their radiolabeling properties at room temperature and $80{ }^{\circ} \mathrm{C}$ with cyclotron-produced ${ }^{44} \mathrm{ScCl}_{3}(0.2 \mathrm{~mL}$ reaction volume, $0.25 \mathrm{M}$ sodium acetate, $\mathrm{pH}$ 4.5). We identified one lead structure, the heptadentate chelator, $\mathrm{H}_{3}$ mpatcn (Fig. 1, radiolabeling trace Fig. 2). $\mathrm{H}_{3}$ mpatcn compared favorably to the DOTA chelator with respect to radiolabeling properties and plasma stability, producing comparable apparent molar activities $\left(0.03 \mathrm{MBq} \mathrm{nmol}^{-1}\right)$ at room temperature and $80{ }^{\circ} \mathrm{C}$ (Table $\mathrm{S} 4 \dagger$ ). Assessment of inertness in rat plasma at $37{ }^{\circ} \mathrm{C}$ revealed the corresponding [Sc(mpatcn)] complex to exhibit minimal detectable transchelation after 2 hours (94.2 $\pm 1.6 \%$ intact complex) comparing well to plasma stability of the DOTA chelator $(95.8 \pm 2.8 \%$ intact complex, Table S5†).

\section{[Sc(mpatcn)] complex characterization}

We employed ${ }^{1} \mathrm{H}$ and ${ }^{45} \mathrm{Sc}$ NMR studies to study and compare the complexation of Sc(III) with DOTA, EDTA and mpatcn chelators. ${ }^{45} \mathrm{Sc}$ NMR provides useful complementary information on shielding of the metal ion by the ligand environment. ${ }^{20,24}$ Fig. 3 and $\mathrm{S} 35 \dagger$ show ${ }^{45} \mathrm{Sc}$ NMR spectra of $[\mathrm{Sc}(\mathrm{DOTA})]^{-}$, $\left[\mathrm{Sc}(\mathrm{EDTA})\left(\mathrm{OH}_{2}\right)_{2}\right]^{-}$and $[\mathrm{Sc}(\mathrm{mpatcn})]$. The corresponding peak chemical shifts were found at 91, 51 and $80 \mathrm{ppm}$ respectively at $\mathrm{pH}$ 7. The Sc(III)-aqua ion in dilute acid produces a sharp signal at 1.3 ppm, while out-of-cage coordination complexes typically result in ${ }^{45} \mathrm{Sc}$ chemical shifts of $20-30 \mathrm{ppm}^{20}$ Low relative chemical shift indicates poor shielding of the ${ }^{45} \mathrm{Sc}$-nucleus from solvent molecules as evidenced by the $\left[\mathrm{Sc}(\mathrm{EDTA})\left(\mathrm{H}_{2} \mathrm{O}\right)_{2}\right]^{-}$ complex (Fig. S36 $†$ ). Our ${ }^{1} \mathrm{H}$ and ${ }^{45}$ Sc NMR data indicates that the Sc(mpatcn) complex does not exhibit significant metal-centered isomerism on the NMR timescale and appears to behave

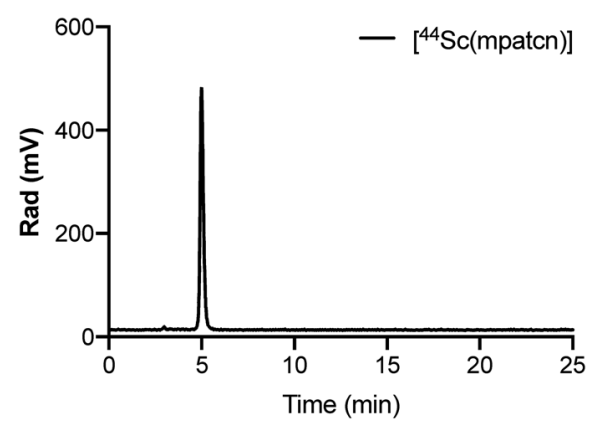

Fig. 2 Representative radioHPLC chromatogram of $\left[{ }^{44} \mathrm{Sc}\right.$ (mpatcn)] after $10 \mathrm{~min}$ incubation at $80^{\circ} \mathrm{C}$, method $\mathrm{D}$. 


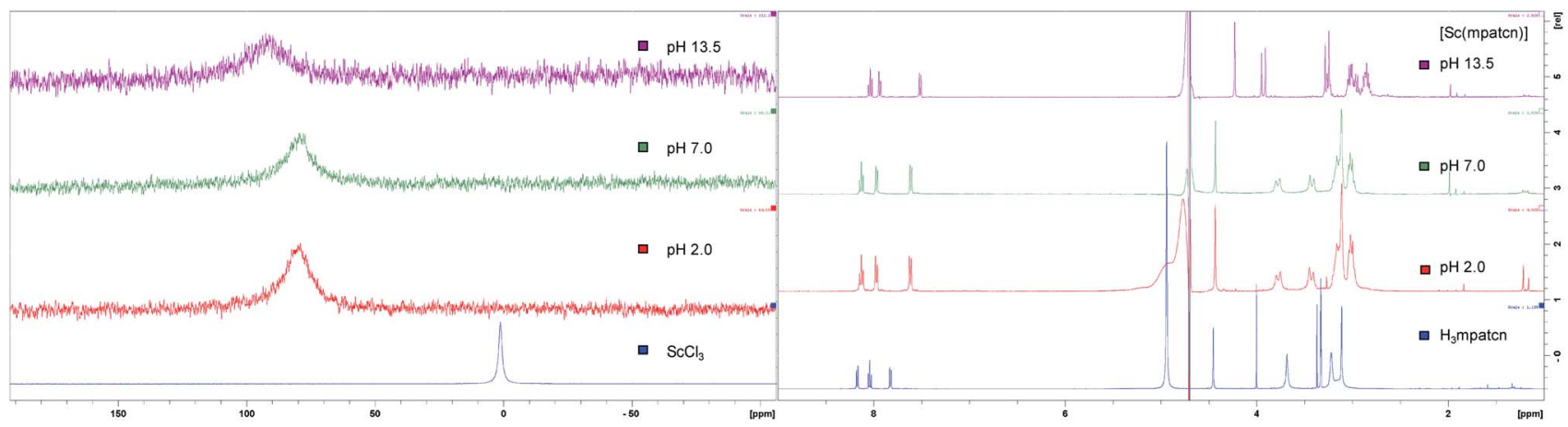

Fig. 3 Representative ${ }^{45} \mathrm{Sc}$ (left) and ${ }^{1} \mathrm{H}$ NMR (right) spectra of $\mathrm{H}_{3} \mathrm{mpatcn} / \mathrm{Sc}^{3+}$ (blue), [Sc(mpatcn)] (red - $\left.\mathrm{pH} 2, \mathrm{green}-\mathrm{pH} 7\right)$ and $[\mathrm{Sc}(\mathrm{mpatcn})(\mathrm{OH})]^{-}$(purple).

comparably to the previously reported $[\mathrm{Lu}(\mathrm{mpatcn})]$ complex ${ }^{29}$ while it is not possible to determine the number of waters bound to the metal ion, NMR experiments indicate that the $\mathrm{H}_{3}$ mpaten ligand can shield $\mathrm{Sc}(\mathrm{III})$ from the solvent environment more efficiently than EDTA, but less efficiently than DOTA, hinting at the presence of one inner-sphere water molecule.

These results are in accordance with NMR-spectroscopic studies on the 8-coordinate, ternary $\left[\mathrm{Sc}(\mathrm{AAZTA})\left(\mathrm{OH}_{2}\right)\right]^{-}$ complex. $^{24}$ To further elucidate the speciation of the [Sc(mpatcn)] complex under radiochemically and physiologically relevant $\mathrm{pH}$ conditions, we carried out $\mathrm{pH}$-titrations followed by NMR $\left({ }^{1} \mathrm{H}\right.$ and ${ }^{45} \mathrm{Sc}$, Fig. 3 and 4$)$ and spectrophotometric methods from $\mathrm{pH} 1.15$ to 13.4.

As characteristic absorbance bands of the ligand exhibit only a small bathochromic shift upon complexation (Fig. S38†), we utilized ${ }^{1} \mathrm{H}$ NMR spectral data to quantitate the presence of different ligand and complex species; Table $\mathrm{S} 1 \dagger$ summarizes characteristic chemical shifts and corresponding structural assignments. Both methods identified the presence of two speciation events. At $\mathrm{pH} 2$, the formation of the [ $\mathrm{Sc}(\mathrm{mpatcn})]$ complex was observed by an increase in absorbance at $280 \mathrm{~nm}$

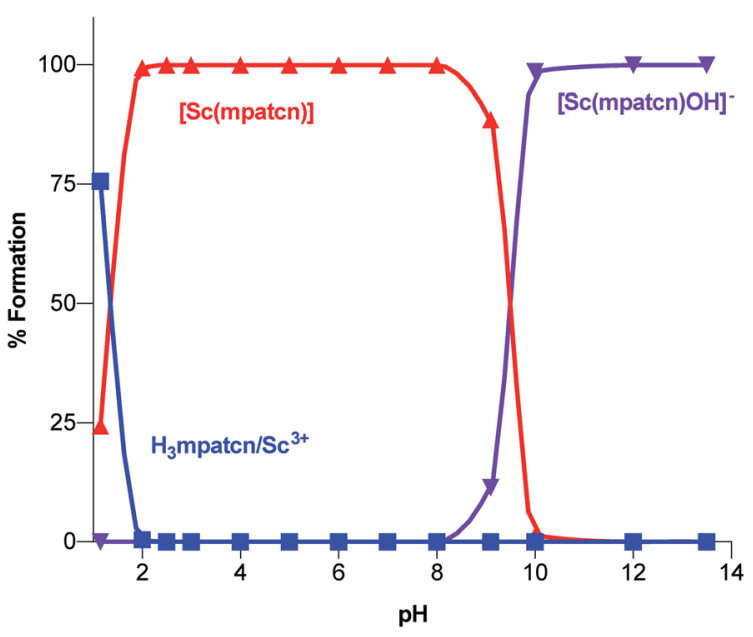

Fig. 4 Complex speciation diagram based on ${ }^{1} \mathrm{H}$ NMR data acquired at $\mathrm{pH}$ values ranging from 1.15-13.4, connecting curves are drawn between individual points for guidance.
(Fig. S38†), coinciding with an upfield shift of the picolinate protons and appearance of diastereotopic methylene proton signals in the 2-4 ppm range in the ${ }^{1} \mathrm{H}$ NMR spectrum (Fig. 3). The corresponding ${ }^{45} \mathrm{Sc}$ NMR shows formation of the in-cage complex at $80 \mathrm{ppm}$. We did not observe formation of an intermediate, protonated complex $[\mathrm{Sc}(\mathrm{Hmpatcn})]^{+}$by ${ }^{1} \mathrm{H}$ NMR or formation of detectable out-of-cage ${ }^{45} \mathrm{Sc}$-species at $\mathrm{pH}$ 2. This behavior contrasts observations made for DOTA, DTPA and AAZTA species under low $\mathrm{pH}$ conditions. ${ }^{19,24}$ We cautiously hypothesize that the lack of the protonated intermediate also favors the rapid in-cage-complex formation to produce the [Sc(mpatcn)] complex, while disfavoring the formation of a stable out-of-cage species. Following the formation of the [ $\mathrm{Sc}(\mathrm{mpatcn})]$ complex species, no formation of new species was observed below $\mathrm{pH} 9$, where evidence for the $[\mathrm{Sc}(\mathrm{mpatcn})(\mathrm{OH})]^{-}$species arises in the form of an upfield shift of the aromatic proton signals and more pronounced diastereotopic splitting of the methylene and azamacrocycle ring protons (Fig. 3 and Table S1†). The $[\mathrm{Sc}(\mathrm{mpatcn})(\mathrm{OH})]^{-}$species dominates above $\mathrm{pH} 10$ and exhibits a ${ }^{45} \mathrm{Sc}$ chemical shift of $89 \mathrm{ppm}$, clearly distinct and more downfield from the corresponding aqua-species. The formation of a hydroxo-species is typical for a hydrolytic, strongly Lewis acidic ion such as $\mathrm{Sc}$ (III) but represents a stark contrast to the speciation of analogous lanthanide complexes, where the formation of hydroxo-complex species is less prevalent. Indeed, the previously characterized $\left[\mathrm{Gd}(\mathrm{mpatcn})\left(\mathrm{OH}_{2}\right)_{2}\right]$ complex does not form below $\mathrm{pH} 4$, nor does it exhibit formation of the hydroxo-bound species even at $\mathrm{pH}>11 .^{28,31}$ Our experiments indicate that under radiochemically and physiologically relevant conditions, the desired $[\mathrm{Sc}(\mathrm{mpatcn})]$ complex species dominates.

\section{Acid-catalyzed complex dissociation}

Under physiological pH conditions, the [Sc(mpaten)] complex remains inert and no complex dissociation can be detected over extended periods of time. In order to compare the inertness of [Sc(mpatcn)] with [Sc(DOTA) $]^{-}$under more forcing conditions, we carried out UV-Vis spectroscopy-assisted measurement of dissociation constants and half-lives at proton concentrations ranging from $3-0.1 \mathrm{M}$ (Table $\mathrm{S} 3 \dagger$ ). ${ }^{19}$ Rates of dissociation decrease rapidly as proton concentration is diminished, with a $k_{\text {obs }}$ of $6.5 \times 10^{-5} \mathrm{~s}^{-1}$ and a $t_{1 / 2}$ of $179.6 \mathrm{~min}$ at $0.1 \mathrm{M}$, 
indicating that even at $\mathrm{pH} 1$, the acid-mediated decomplexation rate is slow. At proton concentrations below $0.1 \mathrm{M}$, the acidmediated dissociation was too slow to be measured by UV-Vis spectroscopic methods.

These experiments allow us to conclude that acid mediated decomplexation poses no significant concerns for in vivo applications of $[\mathrm{Sc}(\mathrm{mpatcn})]$ at physiological conditions.

\section{Functionalization of mpatcn:picaga}

Based on the promising results obtained with the nonfunctionalized chelator, we synthesized a proof-of-concept bioconjugate, to incorporate a biological targeting vector, 2-[3-(1,3dicarboxypropyl)ureido]pentanedioic acid (DUPA)..$^{32,33}$ DUPA targets the prostate specific membrane antigen (PSMA) overexpressed in a large fraction of metastasizing prostate cancers; ${ }^{34}$ additionally, the growing number of studies with PSMAtargeting nuclear probes evaluated in preclinical and human data provides a suitable reference to probe the efficacy of a novel conjugate. ${ }^{\mathbf{8 , 9 3 5 - 3 9}}$ We elected to substitute the mpatcn ligand via a functionalized glutarate in close analogy to the 6-coordinate NODAGA and 8-coordinate DOTAGA chelators to preserve the original ligand donor set as closely as possible. ${ }^{6,40,41}$ This contrasts the mono-amidation conjugation strategy commonly employed for PSMA-targeted DOTA-conjugates, which converts one of the coordinating carboxylates into an amide. ${ }^{\mathbf{1 0}}$ Amide coordination to the $\mathrm{Sc}$ (III) ion would impart a significantly altered coordination environment with a greater, not directly predictable impact on the radiolabeling properties and corresponding kinetic inertness. The functionalized mpaten derivative, picaga-DUPA (Fig. 5), was synthesized by alkylation of triazacyclononane with benzyl(methyl-sulfonyloxy)-glutarate, followed by step-wise introduction of tert-butyl-6(bromomethyl)-2-pyridinecarboxylate, followed by alkylation with tert-butyl-bromoacetate (Scheme 1). Each alkylated intermediate was isolated and purified using reverse-phase preparative HPLC (method A). Following the complete assembly of the orthogonally protected ligand, the benzyl-ester was deprotected and amidated with the $t$-butyl ester protected form of aminopentyl-functionalized DUPA. ${ }^{32,42,43}$ A direct DO3Amonoamide DUPA conjugate analogue was also synthesized (ESI, $\uparrow$ compound 17). The fully assembled conjugates picagaDUPA (15) and DOTA-DUPA (17) were deprotected and characterized using ${ }^{1} \mathrm{H}$ NMR, ${ }^{13} \mathrm{C}$ NMR and mass spectrometry. Following complete characterization, the non-radioactive scandium complexes were formed and characterized using HPLC-analysis and mass spectrometry. The glutarate arm is introduced as the $R$-enantiomer, with the alpha carbon subsequently introducing a stereocenter to the ligand. ${ }^{\mathbf{4 4 , 4 5}}$ Upon coordination to $\mathrm{Sc}$ (III) this results in the formation of kinetically inert diastereomers with distinct HPLC-retention times (Fig. 6A). The formation of coordinative diastereomers has been observed and characterized for similar molecules of this

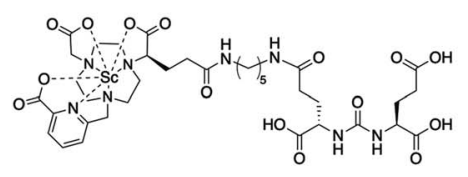

Sc(picaga)-DUPA, Sc(15)

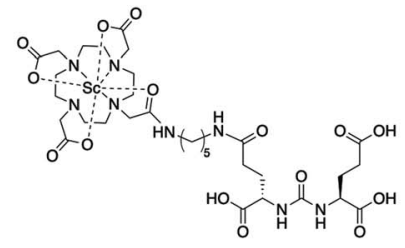

Sc(DOTA)-DUPA, Sc(17)

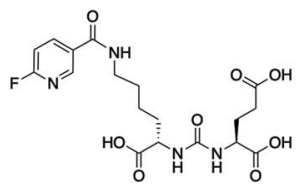

DCFPyL

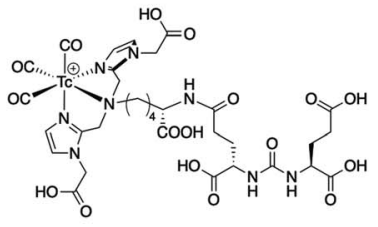

MIP-1427

Fig. 5 PSMA-conjugates synthesized and utilized to determine comparative receptor binding affinity and biodistribution.

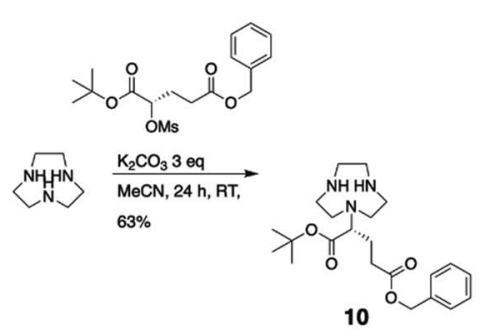

10
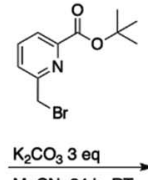
MeCN, $24 \mathrm{~h}, \mathrm{RT}$ $20 \%$
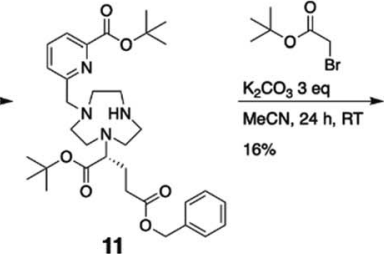

TFADCM (1:1)

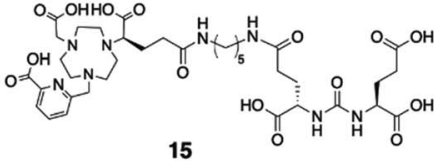

$12 \mathrm{~h}, \mathrm{RT}$

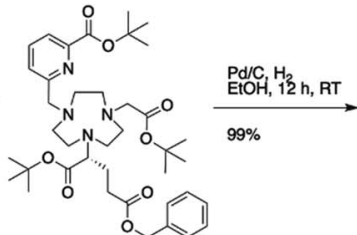

12
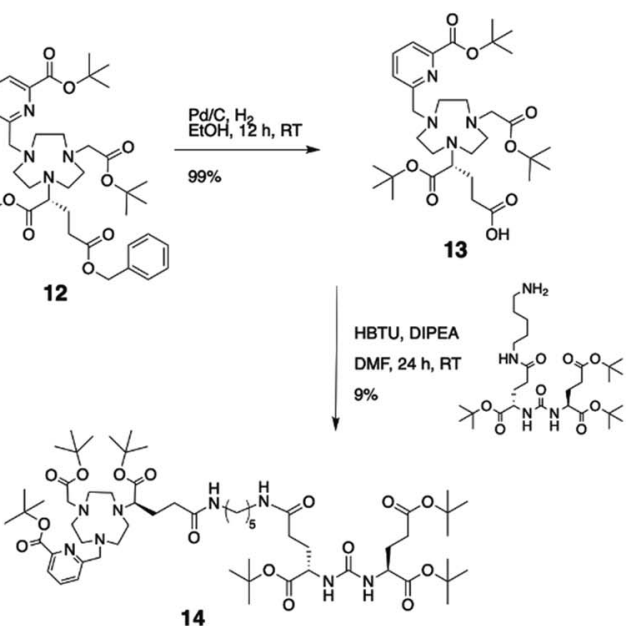

Scheme 1 Step-wise chemical synthesis of picaga-DUPA (15) including isolated yields. 


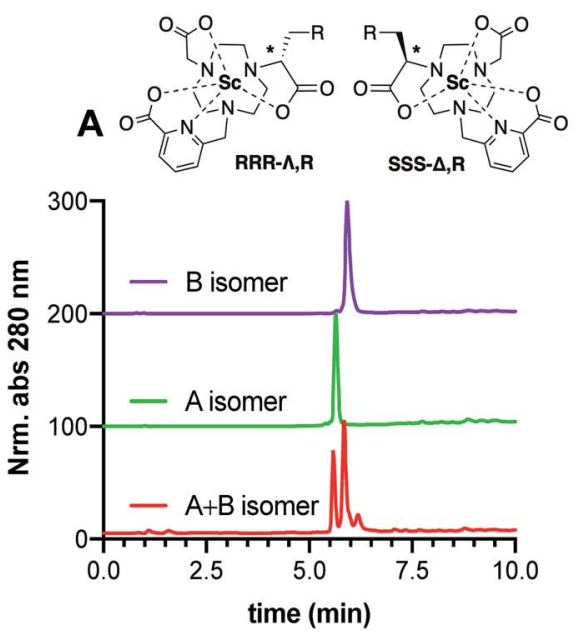

B

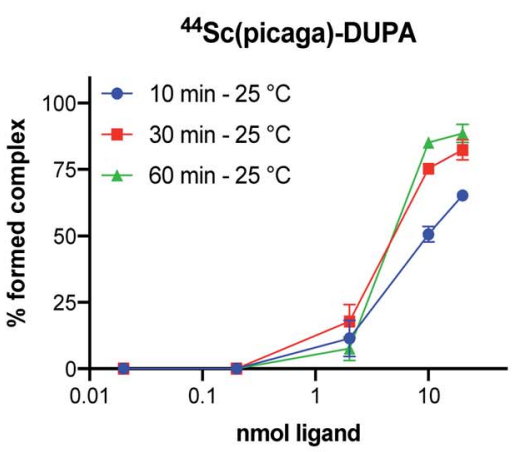

C

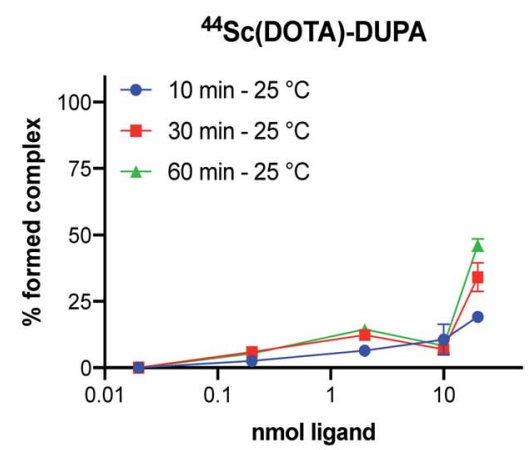

Fig. 6 (A) Characterization of non-interconverting RRR- $\Lambda$ and SSS- $\Delta$-isomers of Sc(picaga)-DUPA using chromatography method C. (B and C) Radiolabeling yields obtained in dependence of increasing amounts of DUPA-conjugate demonstrate superior radiolabeling properties at room temperature for the bifunctional picaga chelator when compared with the functionalized DO3A-monoamide structure.

bifunctional compound class, specifically for DOTAGA-type derivatives which display not only $R R R-\Lambda$ and $S S S-\Delta$, but also SAP and TSAP-isomerism on the NMR timescale. ${ }^{46}$ The $\mathrm{Sc}$ (III) $R R R-\Lambda, R$ - and $S S S-\Delta, R$-diastereomers were chromatographically separated and subsequently analyzed for re-isomerization in solution; no interconversion was observed after 18 hours (Fig. S39†), exemplifying the high kinetic inertness of the corresponding diastereomers with respect to isomerization and reaffirming the conformational rigidity of the bifunctional, picolinate-functionalized triaza-macrocycle. ${ }^{47}$

\section{Complexation with ${ }^{44} \mathrm{Sc}$}

DOTA-DUPA and picaga-DUPA conjugates were subjected to radiochemical complexation experiments, testing both time and temperature dependence of complexation reactions. ${ }^{44} \mathrm{Sc}$ (picaga)DUPA produces high radiochemical yields with $10 \mathrm{nmol}$ of conjugate: $83 \%$ complexation was achieved at room temperature and $96 \%$ at $80{ }^{\circ} \mathrm{C}$ (Fig. $6 \mathrm{~B}$ and $\mathrm{S} 41 \dagger$ ). This result is in contrast with radiolabeling results obtained for the non-functionalized mpatcn ligand. We hypothesize that the efficient structural preorganization of the functionalized derivative accelerates room temperature complexation. Results obtained with picaga-DUPA at room temperature compare favorably to radiolabeling of ${ }^{44} \mathrm{Sc}$ with DOTA-conjugates at $95^{\circ} \mathrm{C}$ (Fig. S41, $\dagger 87 \%$ yield with $10 \mathrm{nmol}$ ligand). The radiochemical complexes also form the characteristic diastereomers, with a minor and major stereoisomer separated by 0.5 minute retention time using chromatographic separation. For radiochemical and subsequent in vivo imaging studies, no attempts were made to separate the two diastereomers as the two complexes co-elute when separated from free ${ }^{44} \mathrm{Sc}$ by reverse-phase solid phase extraction.

\section{Binding affinity to PSMA}

In order to produce a bioconjugate with potential to image a biological target, a high binding affinity of the imaging probe is paramount. Picaga-DUPA does not incorporate additional secondary affinity tags by modification of the linker structure as is the case for PSMA-617 complexes. ${ }^{48}$ We reasoned that Sc(picaga)-DUPA exhibited sufficiently lipophilic character and the coordination complex could suffice to produce high binding affinity to the PSMA target without additional linker modifications in analogy with the ${ }^{68} \mathrm{Ga}$-based PET probe PSMA-11. ${ }^{49}$ The difference in lipophilicity is evidenced by the increase in HPLC retention times from $[\mathrm{Sc}(\mathrm{DOTA})]^{-}$(3.7 $\left.\mathrm{min}\right)$ to $\mathrm{Sc}(\mathrm{mpatcn})(5.0$ min), with the same trend observed for the corresponding DUPA conjugate complexes (Table S4 $\dagger$ ). In order to determine the binding affinity of both conjugates, we carried out the chemical synthesis of MIP-1427, a ${ }^{99 \mathrm{~m}}$ Tc-radiolabeled, wellestablished PSMA-targeting imaging probe which has already been evaluated in patients. ${ }^{32,50}$ Following successful synthesis, we carried out a radioactive displacement assay by challenging constant amounts of MIP-1427 with a varying concentration of non-radioactive Sc(III) complex. Non-radioactive DCFPyL was employed as an assay standard and to calculate relative $K_{\mathrm{i}}$ 's based on the obtained $\mathrm{IC}_{50}$ values. Our experiments revealed a $K_{\mathrm{i}}$ value of $1.6 \pm 0.4 \mathrm{nM}$ for Sc(picaga)-DUPA. This value compares well to the compounds with high PSMA-affinity reported in literature, specifically DCFPyL and MIP-1427 (Table 2).

Table 2 Summary of $K_{\mathrm{i}}$ values of PSMA-targeting imaging probes evaluated previously and reported in this manuscript

\begin{tabular}{lc}
\hline Compound & $K_{\mathrm{i}}(\mathrm{nM})$ \\
\hline Sc(picaga)-DUPA & $1.6 \pm 0.4$ \\
Sc(picaga)-DUPA (isomer A) & $3.6 \pm 2.0$ \\
Sc(picaga)-DUPA (isomer B) & $0.2 \pm 0.2$ \\
Sc(DOTA)-DUPA & $222 \pm 186$ \\
DCFPyL & $1.1 \pm 0.2$ \\
MIP-1427 (ref. 32) & $0.6 \pm 0.5$ \\
Ga-PSMA-11 (ref. 49) & $12.0 \pm 2.8$ \\
Sc-PSMA-617 (ref. 51) & $4.7 \pm 0.8$
\end{tabular}


A

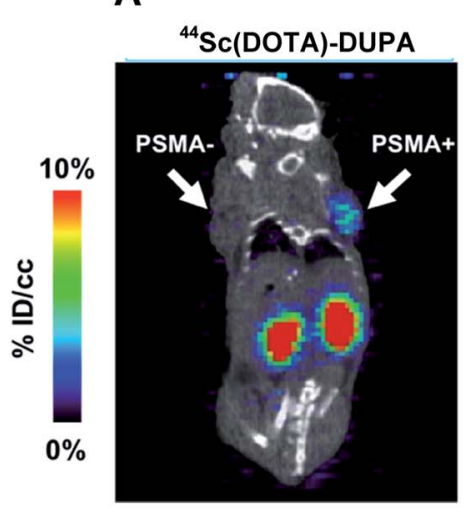

B

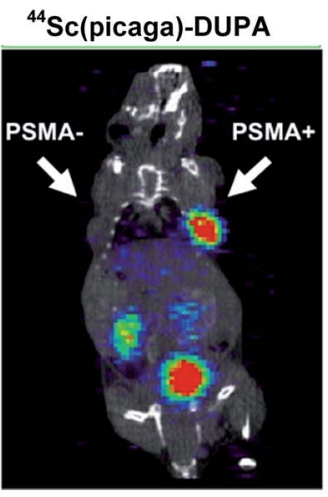

C

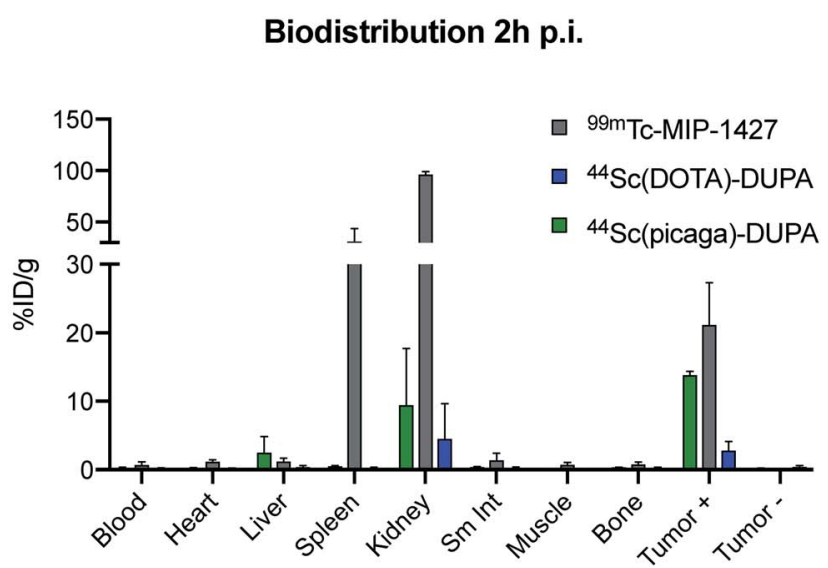

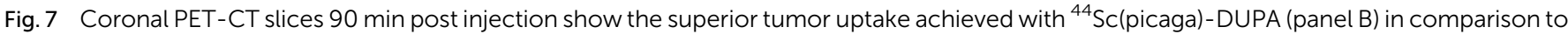
${ }^{44}$ Sc-DOTA-DUPA (panel A), confirmed by the results obtained from the biodistribution analysis 120 min post injection (panel C).

Sc(DOTA)-DUPA exhibits a two orders of magnitude lower binding affinity, which is in accordance with previously investigated DOTA conjugates ${ }^{49}$ that do not bear a modified lipophilic linker to enhance affinity, in contrast to PSMA-617. As we are able to separate the non-interconverting diastereomers, we also determined the $K_{\mathrm{i}}$ of the A isomer and the B isomer separately. We found that the $\mathrm{B}$ isomer exhibited a 10-fold greater binding affinity $(0.2 \pm 0.2 \mathrm{nM})$ than the A isomer $(3.6 \pm 2.0 \mathrm{nM})$. This discrepancy in $K_{\mathrm{i}}$ values indicates that the structure $\mathrm{Sc}$ coordination complex plays a significant role in bonding of the conjugate with the target.

\section{In vivo imaging and biodistribution experiments}

To assess the in vivo behavior of ${ }^{44} \mathrm{Sc}$ (picaga)-DUPA and applicability to targeted in vivo imaging, we administered the radiolabeled compound to mice bearing PSMA+ (PC-3 PiP) and PSMA- (PC-3 Flu) tumor xenografts on the right and the left flank respectively. ${ }^{37,42}$ As a reference, the corresponding ${ }^{44} \mathrm{Sc}$ DOTA-DUPA and ${ }^{99 \mathrm{~m}}$ Tc-labeled MIP-1427 complexes were also synthesized and evaluated in vivo. Mice were imaged at 90 minutes post injection using PET-CT for ${ }^{44}$ Sc-labeled compounds (Fig. 7A and B). All cohorts were sacrificed at 120 minutes post injection for biodistribution analysis.

The animal studies reveal that ${ }^{44} \mathrm{Sc}$ (picaga)-DUPA exhibits excellent properties for in the vivo imaging of PSMA+ cancer xenografts; the uptake achieved with ${ }^{44} \mathrm{Sc}$ (picaga)-DUPA was $13.8 \pm 0.6 \%$ ID per $g$, which supersedes uptake observed for the corresponding DOTA conjugate $(2.8 \pm 1.3 \%$ ID per g) evaluated in this study and compares well to the tumor uptake observed with MIP-1427 (21.2 $\pm 6.2 \%$ ID per g) (Fig. 6C). The difference in uptake between the DOTA and picaga conjugates likely arises from the enhanced binding affinity to the target for ${ }^{44} \mathrm{Sc}$ (picaga)-DUPA, and possibly also from slower blood clearance of the latter. The increased lipophilicity of ${ }^{44} \mathrm{Sc}$ (picaga)DUPA conjugate also affects the path of excretion as evidenced by enhanced hepatic clearance, contrasting the almost exclusively renally clearing DOTA conjugate; other picolinate- derivatized complex conjugates have been reported to exhibit similar in vivo behavior. ${ }^{52,53}$ Notably, in comparison with MIP1427 , kidney and splenic uptake are low; this bodes especially well for prospective therapeutic applications with ${ }^{47} \mathrm{Sc}$ where elevated kidney uptake can become a dosimetric concern.

\section{Conclusions}

We have employed lanthanide-chemistry based design principles and a medicinal inorganic chemistry screening approach to identify the picolinate-functionalized, triaza-macrocycle-based chelator $\mathrm{H}_{3}$ mpatcn as a suitable ligand to coordinate trivalent scandium rapidly and form kinetically inert coordination complexes under macroscopic and tracer conditions. Investigations of the complex formation using optical and NMR spectroscopy, as well as $\mathrm{pH}$ dependent speciation experiments revealed that $\mathrm{H}_{3}$ mpatcn complexes $\mathrm{Sc}$ at $\mathrm{pH} 2$ to form the desired in-cage complex species. The corresponding, neutral, heptacoordinate [Sc(mpatcn)] complex species dominates in the $\mathrm{pH}$ range from 2 to 9 with putative coordination of a single water molecule as the eighth donor within the inner sphere, in close analogy to [Sc(AAZTA) $]^{-}$. A bifunctional chelate was furnished and appended to the PSMA-targeting dipeptide DUPA, a targeting vector which has been clinically employed for the imaging of PSMA-expressing prostate cancers. The corresponding conjugate picaga-DUPA forms inert, diastereotopic $R R R-\Lambda, R$ and $S S S-\Delta, R$-twist-isomer complexes with Sc(III). The preorganized structure of picaga enables radiolabeling at room temperature with $60 \mathrm{MBq} \mu \mathrm{mol}^{-1}$ apparent molar activity while retaining complex inertness in rat plasma. A competitive binding assay was carried out to evaluate the affinity of the Sc(picaga)-DUPA conjugate to the PSMA-target; an exceptionally high binding affinity of the complex $\left(K_{\mathrm{i}}=1.6 \pm 0.4 \mathrm{nM}\right)$ was affirmed. Finally, an in vivo imaging and biodistribution study with ${ }^{44} \mathrm{Sc}$ (picaga)-DUPA demonstrates efficacy of the conjugate to image PSMA+ tumors. The high target tumor uptake and favorable biodistribution profile comparable to clinically 
validated MIP-1427 qualifies ${ }^{44} \mathrm{Sc}$ (picaga)-DUPA as a tracer with excellent characteristics for future clinical translation and suitable for tandem radiotherapeutic applications with ${ }^{47} \mathrm{Sc}$.

In summary, we demonstrate that $\mathrm{H}_{3}$ mpaten and its bifunctional analogue picaga represent excellent additions to the chelator toolbox for the emerging ${ }^{44 / 47} \mathrm{Sc}$ theragnostic isotope pair. Future studies are focused on expanding the scope of diseases imaged with picaga-conjugates, treatment studies with ${ }^{47} \mathrm{Sc}$ (picaga)-DUPA and evaluation of $\mathrm{H}_{3}$ mpaten for the complexation of other lanthanides and pseudolanthanides of interest for biomedical imaging applications.

\section{Ethical statement}

All animal experiments and procedures were performed in accordance with the National Institutes of Health's "Guide for the Care and Use of Laboratory Animals" and approved by Institutional Animal Care and Use Committee (IACUC) at Stony Brook Medicine.

\section{Conflicts of interest}

There are no conflicts to declare.

\section{Acknowledgements}

Financial support for this work was provided by the National Institutes of Health (NIH) via a Pathway to Independence Award (NHLBI R00HL125728-04), a LIBH REACH grant (U01HL12752218150031) and Stony Brook University for startup funds. Peter Smith-Jones is acknowledged for providing DCFPyL.

\section{References}

1 J. Notni and H. J. Wester, J. Labelled Compd. Radiopharm., 2018, 61, 141-153.

2 F. Rösch and R. P. Baum, Dalton Trans., 2011, 40, 6104-6111. 3 S. M. Qaim, B. Scholten and B. Neumaier, J. Radioanal. Nucl. Chem., 2018, 318, 1493-1509.

4 C. Müller, M. Bunka, S. Haller, U. Köster, V. Groehn, P. Bernhardt, N. van der Meulen, A. Türler and R. Schibli, J. Nucl. Med., 2014, 55, 1658-1664.

5 D. J. Kwekkeboom, W. W. de Herder, B. L. Kam, C. H. van Eijck, M. van Essen, P. P. Kooij, R. A. Feelders, M. O. van Aken and E. P. Krenning, J. Clin. Oncol., 2008, 26, 2124-2130.

6 A. Heppeler, S. Froidevaux, H. Mäcke, E. Jermann, M. Béhé, P. Powell and M. Hennig, Chem.-Eur. J., 1999, 5, 1974-1981.

7 M. V. Deshmukh, G. Voll, A. Kühlewein, H. Mäcke, J. Schmitt, H. Kessler and G. Gemmecker, J. Med. Chem., 2005, 48, 1506-1514.

8 M. Weineisen, M. Schottelius, J. Simecek, R. P. Baum, A. Yildiz, S. Beykan, H. R. Kulkarni, M. Lassmann, I. Klette and M. Eiber, J. Nucl. Med., 2015, 56, 1169-1176.

9 M. Schottelius, M. Wirtz, M. Eiber, T. Maurer and H.-J. Wester, EJNMMI Res., 2015, 5, 68.
10 C. A. Umbricht, M. Benešová, R. M. Schmid, A. Türler, R. Schibli, N. P. van der Meulen and C. Müller, EJNMMI Res., 2017, 7, 9.

11 G. Flux, M. Bardies, M. Monsieurs, S. Savolainen, S.-E. Strand and M. Lassmann, Z. Med. Phys., 2006, 16, 4759.

12 D. McGowan and M. Guy, Br. J. Radiol., 2015, 88, 20140720.

13 C. A. Umbricht, M. Benešová, R. M. Schmid, A. Türler, R. Schibli, N. P. van der Meulen and C. Müller, EJNMMI Res., 2017, 7, 9.

14 I. F. Chaple and S. E. Lapi, J. Nucl. Med., 2018, 59, 1655-1659. 15 K. A. Domnanich, C. Müller, M. Benešová, R. Dressler, S. Haller, U. Köster, B. Ponsard, R. Schibli, A. Türler and N. P. van der Meulen, EJNMMI Radiopharmacy and Chemistry, 2017, 2, 5.

16 K. A. Domnanich, C. Müller, R. Farkas, R. M. Schmid, B. Ponsard, R. Schibli, A. Türler and N. P. van der Meulen, EJNMMI Radiopharmacy and Chemistry, 2017, 1, 8.

17 M. Pruszyński, A. Majkowska-Pilip, N. S. Loktionova, E. Eppard and F. Roesch, Appl. Radiat. Isot., 2012, 70, 974979.

18 R. Hernandez, H. F. Valdovinos, Y. Yang, R. Chakravarty, H. Hong, T. E. Barnhart and W. Cai, Mol. Pharmaceutics, 2014, 11, 2954.

19 M. Pniok, V. Kubíček, J. Havlíčková, J. Kotek, A. Sabatie-Gogová, J. Plutnar, S. Huclier-Markai and P. Hermann, Chem.-Eur. J., 2014, 20, 7944-7955.

20 R. Kerdjoudj, M. Pniok, C. Alliot, V. Kubíček, J. Havlíčková, F. Rösch, P. Hermann and S. Huclier-Markai, Dalton Trans., 2016, 45, 1398-1409.

21 M. Pérez-Malo, G. Szabó, E. Eppard, A. Vagner, E. Brücher, I. Tóth, A. Maiocchi, E. H. Suh, Z. n. Kovács and Z. Baranyai, Inorg. Chem., 2018, 57, 6107-6117.

22 A. Majkowska-Pilip and A. Bilewicz, J. Inorg. Biochem., 2011, 105, 313-320.

23 T. I. Kostelnik and C. Orvig, Chem. Rev., 2019, 119, 902-956. 24 G. Nagy, D. Szikra, G. Trencsényi, A. Fekete, I. Garai, A. M. Giani, R. Negri, N. Masciocchi, A. Maiocchi, F. Uggeri, I. Tóth, S. Aime, G. Giovenzana and Z. Baranyai, Angew. Chem., Int. Ed., 2017, 56, 2118-2122.

25 J.-P. Sinnes, J. Nagel and F. Rösch, EJNMMI Radiopharmacy and Chemistry, 2019, 4, 18.

26 C. Alliot, R. Kerdjoudj, N. Michel, F. Haddad and S. HuclierMarkai, Nucl. Med. Biol., 2015, 42, 524-529.

27 E. Aluicio-Sarduy, R. Hernandez, A. P. Olson, T. E. Barnhart, W. Cai, P. A. Ellison and J. W. Engle, Sci. Rep., 2019, 9, 10658. 28 A. Nonat, M. Giraud, C. Gateau, P. H. Fries, L. Helm and M. Mazzanti, Dalton Trans., 2009, 8033-8046.

29 A. M. Nonat, C. Gateau, P. H. Fries, L. Helm and M. Mazzanti, Eur. J. Inorg. Chem., 2012, 2049-2061.

30 J. W. Walton, R. Carr, N. H. Evans, A. M. Funk, A. M. Kenwright, D. Parker, D. S. Yufit, M. Botta, S. De Pinto and K.-L. Wong, Inorg. Chem., 2012, 51, 8042-8056.

31 Y. Bretonnière, M. Mazzanti, J. Pécaut, F. A. Dunand and A. E. Merbach, Chem. Commun., 2001, 621-622.

32 S. M. Hillier, K. P. Maresca, G. Lu, R. D. Merkin, J. C. Marquis, C. N. Zimmerman, W. C. Eckelman, 
J. L. Joyal and J. W. Babich, J. Nucl. Med., 2013, 54, 13691376.

33 C. M. Zechmann, A. Afshar-Oromieh, T. Armor, J. B. Stubbs, W. Mier, B. Hadaschik, J. Joyal, K. Kopka, J. Debus and J. W. Babich, Eur. J. Nucl. Med. Mol. Imaging, 2014, 41, 1280-1292.

34 A. Ghosh and W. D. Heston, J. Cell. Biochem., 2004, 91, 528539.

35 A.-C. Baranski, M. Schäfer, U. Bauder-Wüst, M. Roscher, J. Schmidt, E. Stenau, T. Simpfendörfer, D. Teber, L. Maier-Hein and B. Hadaschik, J. Nucl. Med., 2018, 59, 639-645.

36 R. P. Baum, H. R. Kulkarni, C. Schuchardt, A. Singh, M. Wirtz, S. Wiessalla, M. Schottelius, D. Mueller, I. Klette and H.-J. Wester, J. Nucl. Med., 2016, 115, 168443.

37 Z. Szabo, E. Mena, S. P. Rowe, D. Plyku, R. Nidal, M. A. Eisenberger, E. S. Antonarakis, H. Fan, R. F. Dannals, Y. Chen, R. C. Mease, M. Vranesic, A. Bhatnagar, G. Sgouros, S. Y. Cho and M. G. Pomper, Mol. Imaging Biol., 2015, 17, 565-574.

38 M. Dietlein, C. Kobe, G. Kuhnert, S. Stockter, T. Fischer, K. Schomäcker, M. Schmidt, F. Dietlein, B. D. Zlatopolskiy and P. Krapf, Mol. Imaging Biol., 2015, 17, 575-584.

39 M. Benešová, M. Schäfer, U. Bauder-Wüst, A. AfsharOromieh, C. Kratochwil, W. Mier, U. Haberkorn, K. Kopka and M. Eder, J. Nucl. Med., 2015, 56, 914-920.

40 K.-P. Eisenwiener, P. Powell and H. R. Mäcke, Bioorg. Med. Chem. Lett., 2000, 10, 2133-2135.

41 K.-P. Eisenwiener, I. M. Prata, I. Buschmann, H. W. Zhang, A. C. Santos, S. Wenger, J. C. Reubi and H. R. Mäcke, Bioconjugate Chem., 2002, 13, 530-541.

42 S. R. Banerjee, M. Pullambhatla, C. A. Foss, S. Nimmagadda, R. Ferdani, C. J. Anderson, R. C. Mease and M. G. Pomper, J. Med. Chem., 2014, 57, 2657-2669.
43 Y. Chen, M. Pullambhatla, S. R. Banerjee, Y. Byun, M. Stathis, C. Rojas, B. S. Slusher, R. C. Mease and M. G. Pomper, Bioconjugate Chem., 2012, 23, 2377-2385.

44 S. G. Levy, V. Jacques, K. L. Zhou, S. Kalogeropoulos, K. Schumacher, J. C. Amedio, J. E. Scherer, S. R. Witowski, R. Lombardy and K. Koppetsch, Org. Process Res. Dev., 2009, 13, 535-542.

45 K. Overoye-Chan, S. Koerner, R. Looby, A. Kolodziej, S. Zech, Q. Deng, J. Chasse, T. McMurry and P. Caravan, J. Am. Chem. Soc., 2008, 130, 6025-6039.

46 S. Aime, M. Botta, Z. Garda, B. E. Kucera, G. Tircso, V. G. Young and M. Woods, Inorg. Chem., 2011, 50, 79557965.

47 J. W. Walton, L. Di Bari, D. Parker, G. Pescitelli, H. Puschmann and D. S. Yufit, Chem. Commun., 2011, 47, 12289-12291.

48 M. Benešová, U. Bauder-Wüst, M. Schäfer, K. D. Klika, W. Mier, U. Haberkorn, K. Kopka and M. Eder, J. Med. Chem., 2016, 59, 1761-1775.

49 M. Eder, M. Schäfer, U. Bauder-Wüst, W.-E. Hull, C. Wängler, W. Mier, U. Haberkorn and M. Eisenhut, Bioconjugate Chem., 2012, 23, 688-697.

50 H. Rathke, A. Afshar-Oromieh, F. L. Giesel, C. Kremer, P. Flechsig, S. Haufe, W. Mier, T. Holland-Letz, M. De Bucourt and T. Armor, J. Nucl. Med., 2018, 117, 200220.

51 E. Eppard, A. de la Fuente, M. Benešová, A. Khawar, R. A. Bundschuh, F. C. Gärtner, B. Kreppel, K. Kopka, M. Essler and F. Rösch, Theranostics, 2017, 7, 4359.

52 E. M. Gale, I. P. Atanasova, F. Blasi, I. Ay and P. Caravan, J. Am. Chem. Soc., 2015, 137, 15548-15557.

53 N. A. Thiele, V. Brown, J. M. Kelly, A. Amor-Coarasa, U. Jermilova, S. N. MacMillan, A. Nikolopoulou, S. Ponnala, C. F. Ramogida, A. K. Robertson, C. RodríguezRodríguez, P. Schaffer, C. J. Williams, J. Babich, V. Radchenko and J. Wilson, Angew. Chem., Int. Ed., 2017, 56, 14712-14717. 